\title{
Studies on Variability of Different Cashew Landraces in Bhubaneswar
}

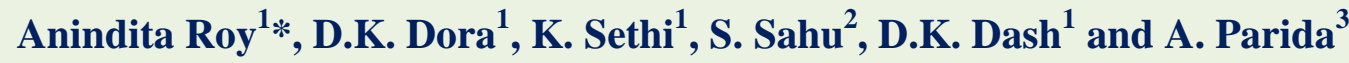 \\ ${ }^{1}$ Department of Fruit science and Horticulture Technology, ${ }^{2}$ Department of Plant Breeding \\ and Genetics, ${ }^{3}$ Department of Agricultural Statistics, University of Agriculture and \\ Technology, Bhubaneswar 751003 Odisha, India \\ *Corresponding author
}

\section{A B S T R A C T}

\begin{tabular}{|l|}
\hline K e y w o r d s \\
Cashew, Genotypic \\
coefficient variation, \\
Phenotypic \\
coefficient variation, \\
Heritability \\
percentage and \\
Genetic advance \\
\hline Article Info \\
\hline $\begin{array}{l}\text { Accepted: } \\
\text { 07 November } 2018 \\
\text { Available Online: } \\
\text { 10 December } 2018\end{array}$ \\
\hline
\end{tabular}

\section{Introduction}

Cashew is a versatile tree nut with multifarious uses. It is a precious gift of nature to mankind among various nuts as hazelnuts, almonds etc. it is considered as 'Gold Mine' of wastelands as it requires low inputs for production and checks soil erosion, It is one of the most important dollar earning plantation crops of India. As a whole, cashew nut is a established food item that can protect human beings against major diseases like cancer, diabetics, heart diseases, etc. with its rare combination of carbohydrates, protein and
An investigation was carried out at cashew research station under AICRP on cashew Ranasinghapur, Bhubaneswar, Khurda, during the year 2015-2017, to study the variability in thirty land races of cashew. It was found that, the heritability was highest in canopy area per $\mathrm{m}^{2}(99.82 \%)$ and minimum was recorded in canopy spread north-south $(61.54 \%)$. The genetic variability with heritability gives a reliable picture of the genetic advance to be expected for the selection. More than $90 \%$ heritability was recorded in characters like, canopy area, total no of laterals, flowering laterals, duration of flowering, panicle length and panicle breadth, sex ratio, cashew apple weight and TSS. The characters like total flowers per panicle, staminate flowers per panicle showed maximum genetic advance. The per parameters will give insight into the inter-relationship among different traits and selection of promising traits are essential to formulate successful breeding programme. fats,. Now, the total production of cashew in the country is $7.79 \mathrm{M}$ tones from 10.35 lakh hectare area (Horticultural statistics at a glance. 2016-17). Most of the area under cashew is in the East-Coast and West-Coast regions of the country. In Odisha, productivity of cashew is about $513 \mathrm{~kg}$ / ha from an area of 183.3 thousand hectare (Horticultural statistics at a glance. 2016-17). Higher productivity of cashew is under Maharashtra and it is due to better adaptation of agro techniques, high yielding clones, better soil fertility conditions etc. On the other hand, in Odisha most of the old cashew plantations are grown in unfertile 
soils with low yielding seedling plants and lack of proper production technology etc. The major constraints of low production of cashew are due to poor management and inferior genetic stock. The success of plant breeding depends on significant level of genetic variability in the original population followed by an efficient selection method for fixation of desirable genetic combinations. Productivity of cashew nut can be increased many fold by using clonal planting material of improved genotypes. Elite cashewnut genotypes have to be bred, before they are cloned. Production of elite genotypes is one of the main mandates of crop improvement programme in All India Co-ordinated Research Project (AICRP) on cashew. The present investigation was carried out to critically study the genetic variability of thirty land races of Cashew.

\section{Materials and Methods}

An experiment was conducted at All India Coordinate Research Project on cashew O.U.A.T., Bhubaneswar, with a latitude of $20^{0} 15^{\prime} \mathrm{N}$, longitude of $85^{\circ} 52^{\prime} \mathrm{E}$ and altitude of 25.5 meters above the mean sea level. It is situated $70 \mathrm{~km}$ away from the Bay of Bengal and falls under the East coastal plains and Hills zone of the humid tropics of India. The texture of soil is sandy loam Sand (81.2 $\%)$,Silt (1.2 \%), Clay (17.6\%), Available water holding capacity $(6.9 \%)$, Soil $\mathrm{pH}$ of 5.1, $\mathrm{EC}\left(\mathrm{dsm}^{-1}\right)$ 0.02, Available Nitrogen $(88 \mathrm{~kg} / \mathrm{ha})$, Available $\mathrm{P}_{2} \mathrm{O}_{5}(28.1 \mathrm{~kg} / \mathrm{ha})$, Available $\mathrm{K}_{2} \mathrm{O}$ $(80.2 \mathrm{~kg} / \mathrm{ha})$. The experiment was laid in randomized block design with two replication and thirty treatments at the age of 16 years of plantation and observations were recorded, as per the standard descriptors of cashew (IBPGR, 1986; Swamy et al., 1998) for two seasons. Recommended package of practices were adopted uniformly to raise a good crop. The present study was undertaken during the fruiting season 2015-2017 of 16 years old cashew plants. Data were recorded on various components of variability. adopting standard procedure as described in the Experimental Manual on Cashew (Experimental Manual on cashew,2005) The genotypes were classified as high( $\mathrm{H})$ (medium (M) and low (L) basing on over all mean and standard error (S. E.) for each character. Statistical analysis of all the recorded data were done by adopting standard procedure as suggested by Panse and Sukhatme (1978).

\section{Results and Discussion}

It is revealed from the experiment that all the variability components for twenty two characters in thirty genotypes witnessed a significant variation from the pooled data. The genetic variability parameters includes character mean, range, genotypic coefficient of variation (GCV) and phenotypic coefficient of variation (PCV), heritability $\left(\mathrm{h}^{2}\right)$ and genetic advance (GA\%) as percent over mean are presented in Table 1.

The tree height varied from 3.47-7.00 m among the different cashew landraces. The GCV observed was 15.38 percent and PCV was 19.51 percent. The heritability found was 62.17 per cent and genetic advance observed over mean was 24.98 percent. Maximum Plant girth was $95.42 \mathrm{~cm}$ as against a minimum of $46.55 \mathrm{~cm}$. GCV and PCV were, 17.01 and 17.4 percent respectively, with 95.66 percent heritability. Genetic advance over mean observed was 34.28 percent. The East-West canopy spread varied from $4.50 \mathrm{~m}$ to $9.50 \mathrm{~m}$. and GCV for East - West canopy spread was 17.54. While the PCV was 20.87 percent. The heritability observed was 70.62 percent and genetic advance over mean observed was 30.36 percent. The North - South canopy spread was in the range of $5.05 \mathrm{~m}$ to $9.35 \mathrm{~m}$ across the genotypes GCV and PCV were observed to be 14.36 and 18.30 percent. Heritability of 61.54 percent and the genetic advance of 23.20 percent over mean were 
observed. Maximum canopy spread per $\mathrm{m}^{2}$ was 70.73 as against a minimum of 18.56 . GCV and PCV were, 32.05 and 32.08 percent, respectively with 99.82 percent heritability. Genetic advance over mean observed was 65.97 percent. Total laterals per $\mathrm{m}^{2}$ observed was 33.75 as against a minimum of 20.17 across the landraces, GCV and PCV were, 12.49 and 12.63 percent, respectively with 97.86 percent heritability and Genetic advance over mean found was 25.46 percent. A maximum of 30.24 flowering shoots were observed as against the minimum of 17.37 across the landraces. The GCV for this trait was observed to be 13.25 percent and PCV was 13.64 percent, with fairly high level influence of environment. Though heritability was observed to be 94.37 percent and it had 26.53 percent of Genetic advance over mean. A maximum of 122.50 flowering days were observed as against the minimum of 78 days across the landraces. The GCV for this trait was observed to be 9.70 percent and PCV was 9.76percent, with fairly high level influence of environment. Though heritability was observed to be 98.83 percent and it had 19.88 percent of GA over mean. The length of the inflorescence ranged from $11.45 \mathrm{~cm}$ to 21.85 $\mathrm{cm}$ among the genotypes. The GCV and PCV were 11.45 and 12.06 percent respectively. The magnitude of heritability was 90.19 percent, while the Genetic advance over mean for this trait was observed 22.41 percent. The breadth of the inflorescence was in the range of $12.85 \mathrm{~cm}$ to $24.95 \mathrm{~cm}$. across the genotypes. GCV and PCV were observed to be 15.50 and 16.33 percent. Heritability of 90.08 percent and the genetic advance over mean for this trait was observed 30.31 percent. The no of staminate flower per Panicle varied from 128 to 461 , GCV for Staminate flower per panicle was 26.60. While the PCV was 29.34 with a heritability of 82.23 and genetic advance over mean observed was 49.70 percent. The number of perfect flower per panicle varied from 10 to 156.50 , GCV for perfect Flower per panicle was 67.62 , while the PCV was 72.73 , the heritability found was 86.44 percent and genetic advance over mean for this trait was observed 129.52 percent. The range of number of flower per panicle was observed to be 165 to 588.50, with GCV and PCV of 28.35 and 30.81 percent respectively. The magnitude of heritability found was 84.63 and genetic advance over mean for this trait was observed 53.72 percent. The sex ratio varied from 0.02 to 0.54 among the landraces. The GCV and PCV for sex ratio were 59.73 and 61.10, respectively. High magnitude of heritability of 95.57 percent was observed coupled with genetic advance over mean of 120.30 per cent. The number of nuts per panicle varied from 2.00 to 11.00 across the landraces. The GCV for this trait was 48.44 percent, while PCV was 55.38 percent. The magnitude of heritability was $(76.50 \%)$, while genetic advance over mean found was 87.28 percent. The nut weight of 17.24 was maximum as against the minimum nut weight of $5.00 \mathrm{~g}$. The difference between GCV was (27.63\%) and PCV was $(29.47 \%)$ and it is very narrow for this trait and the percent of heritability was high $(87.89 \%)$ for weight, though genetic advance over mean observed was 53.37percent. The Kernel weight of 3.72 $\mathrm{g}$ was the maximum while $1.44 \mathrm{~g}$ was the minimum among the cashew genotypes. The difference between GCV (19.28\%) and PCV $(22.87 \%)$ was very narrow for this trait indicating the least influence of the environment on this trait. A moderate magnitude of heritability (71.07) was though observed and the genetic advance over mean found was 33.49 percent. The shelling percent varied from 21.60 to 33.56 across the landraces. The GCV was 9.15 percent, while PCV was 11.34 percent. Heritability and genetic advance over mean were at levels of 65.09 and 15.21 percent, respectively for shelling percent across the cashew landraces. The apple weight varied from 24.80 to 106.39g. The GCV and PCV were 33.58 and 
33.62 percent respectively. The heritability of 99.76 percent was recorded; where as genetic advance over mean found was 69.09 percent. The cashew apples had the TSS range of 10.55 to 18.98 brix among the cashew landraces, The GCV and PCV were 14.95 and 14.99 percent respectively where as the heritability of 99.41 percent was recorded, while genetic advance over mean was 30.70 percent. The acid content varied from $0.26 \%$ to $0.88 \%$. The GCV and PCV were 31.66 and 37.24 percent respectively. The heritability of 72.27 percent was recorded; where as genetic advance over mean found was 55.45 percent. The nut yield per tree ranged from 1.60 to $14.96 \mathrm{~kg}$ per tree among the cashew genotypes. For this trait, GCV observed was 40.63 percent. while the PCV was 43.81; However with higher level of environmental influence on this trait, the magnitude of heritability was 86.06 percent, where as the genetic advance over mean for this trait observed was $(77.67 \%)$.

In the present study, the heritability was highest in canopy area per $\mathrm{m} 2$ (99.82) and minimum was recorded in canopy spread north-south (61.54) and more than 90\% heritability was recorded in characters like, canopy area, total no of laterals, flowering laterals, duration of flowering, panicle length and panicle breadth, sex ratio, cashew apple weight and TSS. The present results are in agreement with findings of Lenka et al., (2001). The characters like total flowers per panicle, staminate flowers per panicle showed maximum genetic advance. The genetic advance percentage of mean was recorded highest in numbers of perfect flowers per panicle (129.52) followed by Sex- Ratio (120.3) and these results were in agreement with reports made by Sena et al., (1994). Lenka et al., 1999) observed high estimates of GCV, heritability and genetic gain over mean were observed for sex ratio, nut yield per plant, number of staminate flowers per panicle and number of perfect flowers per panicle in Orissa and also reported on the nature and magnitude of genetic variability and their inter-relationship for nut yield and its ten component traits in 13 types of cashew. High estimates of genotypic coefficients of variation, heritability and genetic advance were observed for nut yield per plant, number of staminate flowers/panicle-and number of perfect flowers/panicle and number of nuts/panicle indicating their reliability for effecting selections for high nut yield. Number of flower per panicles, nut weight and number of nuts per panicle were the best contributors to nut yield and further number of staminate flowers and perfect flowers showed high positive association with nut yield both at genotypic and phenotypic levels. Hence, the study revealed the importance of number of staminate and perfect flowers, number of nuts per panicle, nut weight and nut yield per plant as selection criteria for improvement of nut yield in the cashew types (Lenka et al., 2001). The Variability, Heritability and Genetic advance for morphological and yield traits in cashew and was revealed about existence of considerable genetic variability for all characters (Dasmohapatra et al., 2012). Sharma et.al (2011) experimented on 52 elite genotypes of cashew to assess the genetic variability and genetic divergence present in the material.

Both the phenotypic as well as genotypic coefficient of variation was recorded highest magnitude for number of hermaphrodite flowers per panicle. Similarly the highest heritability and genetic advance as percent of mean was recorded for 100 nut weight. Mohapatra et al., (2018) experimented in eleven genotypes and found High heritability estimates coupled with high genetic advance were observed in yield, sex ratio, and canopy spread $\left(\mathrm{m}^{2}\right)$. This clearly indicated that selection in the desired direction might be quite effective for these three characters. And BH-85 and BH-6 was superior to all other genotypes and recommended for better nut yield in sustainable manner. 
Table.1 Estimation of variability components

\begin{tabular}{|c|c|c|c|c|c|c|c|c|}
\hline $\begin{array}{l}\text { Sl. } \\
\text { No. }\end{array}$ & Character & Mean & Range & GCV & PCV & Heritability (\%) & GA & $\begin{array}{l}\text { GA }(\%) \\
\text { of mean }\end{array}$ \\
\hline 1 & Height & 5.45 & $3.47-7.00$ & 15.38 & 19.51 & 62.17 & 1.36 & 24.98 \\
\hline 2 & Girth & 74.29 & $46.5-95.42$ & 17.01 & 17.40 & 95.66 & 25.47 & 34.28 \\
\hline 3 & Canopy spread E/W & 7.25 & $4.5-9.5$ & 17.54 & 20.87 & 70.62 & 2.20 & 30.36 \\
\hline 4 & Canopy spread N/S & 7.00 & $5.05-9.35$ & 14.36 & 18.30 & 61.54 & 1.62 & 23.20 \\
\hline 5 & Canopy spread/M² & 41.45 & $18.56-70.73$ & 32.05 & 32.08 & 99.82 & 27.34 & 65.97 \\
\hline 6 & Total Laterals/Mtr ${ }^{2}$ & 24.17 & $20.17-33.75$ & 12.49 & 12.63 & 97.86 & 6.15 & 25.46 \\
\hline 7 & Flowering laterals $/ \mathrm{M}^{2}$ & 21.07 & $17.37-30.24$ & 13.25 & 13.64 & 94.37 & 5.59 & 26.53 \\
\hline 8 & $\begin{array}{l}\text { Duration of } \\
\text { Flowering (Days) }\end{array}$ & 101.56 & $78.00-122.50$ & 9.70 & 9.76 & 98.83 & 20.19 & 19.88 \\
\hline 9 & Panicle length $(\mathrm{cm})$ & 18.18 & $12.3-21.85$ & 11.45 & 12.06 & 90.19 & 4.07 & 22.41 \\
\hline 10 & Panicle breadth $(\mathrm{cm})$ & 20.35 & $12.85-24.95$ & 15.50 & 16.33 & 90.08 & 6.17 & 30.31 \\
\hline 11 & $\begin{array}{l}\text { Staminate } \\
\text { Flower/Panicle }\end{array}$ & 282.95 & $128-461$ & 26.60 & 29.34 & 82.23 & 140.64 & 49.70 \\
\hline 12 & Perfect flower/panicle & 52.80 & $10-156.5$ & 67.62 & 72.73 & 86.44 & 68.39 & 129.52 \\
\hline 13 & Total flowers /panicle & 335.76 & $165.5-588.5$ & 28.35 & 30.81 & 84.63 & 180.40 & 53.72 \\
\hline 14 & Sex ratio & 0.18 & $0.02-0.54$ & 59.73 & 61.10 & 95.57 & 0.22 & 120.30 \\
\hline 15 & Nuts/panicle & 4.35 & $2.00-11.00$ & 48.44 & 55.38 & 76.50 & 3.80 & 87.28 \\
\hline 16 & Nut WT (g) & 8.35 & $5.0-17.24$ & 27.63 & 29.47 & 87.89 & 4.46 & 53.37 \\
\hline 17 & Kernal Wt(gm) & 2.39 & $1.44-3.72$ & 19.28 & 22.87 & 71.07 & 0.80 & 33.49 \\
\hline 18 & Shelling $(\%)$ & 28.86 & $21.60-33.56$ & 9.15 & 11.34 & 65.09 & 4.39 & 15.21 \\
\hline 19 & Cashew Apple weight & 48.98 & 24.8-106.39 & 33.58 & 33.62 & 99.76 & 33.84 & 69.09 \\
\hline 20 & TSS( Brix) & 14.32 & $10.50-18.98$ & 14.95 & 14.99 & 99.41 & 4.39 & 30.70 \\
\hline 21 & Acidity (mg) & 0.56 & $0.26-0.88$ & 31.66 & 37.24 & 72.27 & 0.31 & 55.45 \\
\hline 22 & Nut yield (Kg/Plant) & 6.81 & $1.60-14.96$ & 40.64 & 43.81 & 86.06 & 5.29 & 77.67 \\
\hline
\end{tabular}

Aliyu and Awonpetu (2011) stated eleven yield-related plant traits in 33 accessions selected from 3 Nigerian breeding populations were studied to understand the influence of nut size-number trade-off in cashew tree yield. Three-years of data were statistically analyzed for genetic variability estimates and showed that the accessions were significantly different for all the yield-related traits with highest variability in production of hermaphrodite flowers.

It may be concluded that significant variability was recorded among the genotypes for various morpho-economical traits. Selection for nut yield, sex ratio, Total flower and canopy area $\left(\mathrm{m}^{2}\right)$ will be effective in developing high yielding genotypes. The 
genotypes $\mathrm{BH}-6$ and $\mathrm{BH}-85$ recorded maximum for most of the morpho-economic traits indicating that these can be used in hybrid breeding. The genetic variability with heritability gives a reliable picture of the genetic advance to be expected for the selection, while heritability coupled with genetic advance, is an aid in prediction of a valuable conclusion for effective selection based on non phenotypic performance.

\section{References}

Aliyu, O.M and Awonpetu, J.A. 2011. Variability study on nut size and number trade-off a threshold level of optimum yield in cashew, International Journal of Fruit Science, 28 (2):25-31.

Dasmohapatra, R., Rath S. and Patnaik A.K. 2012. Variability, Heritability and Genetic advance for morphological and yield traits in cashew (Anacardium occidentale L.). Journal of Enviornment and Ecology. 30 (3B): 982-984.

Experimental manual on Cashew. 2005. Directorate of Cashew Research, Puttur, Karnataka. Horticultural statistics at a glance. (2016-17).

Lenka, P.C., Samal, S., Mohapatra, K.C. and Dash, D.K.1999. Studies on genetic variability and correlation studies in cashew. Oriss J. Hortic. 27(1):92-96.

Lenka, P.C., Mohapatra, K.C., Dash, S and Mishra, N.K., 2001. Genetic variability and character association in cashew, Horticultural Journal, 14 (2): 105-110.

Mohapatra, M., Dash, D. K., Tripathy, P., Sethi, K., Dash, M. and Roy, A. 2018. Studies on Variability, Heritability and Genetic Advance in cashew (Anacardium occidentale 1.). Trends in Biosciences 11(2): 120-125

Panse, V. G. and Sukhatme, P. V. 1954. Statistical methods of Agricultural Work, ICAR, Publications, New Delhi.

Sena, D.K., Lenka, P.C. and Rath, S. 1995. Studies on floral characters of different cashew types. The cashew 9 (2):5-7.

Sharma, D., Sahu, K.R and Nanda, H.C. 2011. Studies on component of variability and genetic divergence in cashew, Journal of Agricultural Issues, $16(1 \& 2): 47-51$

\section{How to cite this article:}

Anindita Roy, D.K. Dora, K. Sethi, S. Sahu, D.K. Dash and Parida, A. 2018. Studies on Variability of Different Cashew Landraces in Bhubaneswar. Int.J.Curr.Microbiol.App.Sci. 7(12): 433-438. doi: https://doi.org/10.20546/ijcmas.2018.712.054 